

\title{
Do personalities co-vary with metabolic expenditure and glucocorticoid stress response in adult lizards?
}

Hugo Mell, Rémy Josserand, Beatriz Decencière, Paulina Artacho, Sandrine Meylan, Jean-François Le Galliard

\section{- To cite this version:}

Hugo Mell, Rémy Josserand, Beatriz Decencière, Paulina Artacho, Sandrine Meylan, et al.. Do personalities co-vary with metabolic expenditure and glucocorticoid stress response in adult lizards? Behavioral Ecology and Sociobiology, 2016, 10.1007/s00265-016-2117-z . hal-01309742

\section{HAL Id: hal-01309742 \\ https://hal.sorbonne-universite.fr/hal-01309742}

Submitted on 30 Apr 2016

HAL is a multi-disciplinary open access archive for the deposit and dissemination of scientific research documents, whether they are published or not. The documents may come from teaching and research institutions in France or abroad, or from public or private research centers.
L'archive ouverte pluridisciplinaire HAL, est destinée au dépôt et à la diffusion de documents scientifiques de niveau recherche, publiés ou non, émanant des établissements d'enseignement et de recherche français ou étrangers, des laboratoires publics ou privés. 


\section{Do personalities co-vary with metabolic expenditure and}

\section{2 glucocorticoid stress response in adult lizards?}

3 Hugo Mell ${ }^{1}$, Rémy Josserand ${ }^{1}$, Beatriz Decencière ${ }^{2}$, Paulina Artacho ${ }^{3}$, Sandrine Meylan ${ }^{1,4}$ and

4 Jean-François Le Galliard*1,2

5

${ }^{1}$ CNRS/UPMC, UMR 7618, iEES Paris, Université Pierre et Marie Curie, 7 Quai St. Bernard,

7 75005, Paris, France

$8 \quad{ }^{2}$ CNRS/ENS UMS 3194, CEREEP - Ecotron IleDeFrance, École Normale Supérieure, 78 rue

9 du Château, 77140 St-Pierre-lès-Nemours

$10{ }^{3}$ Instituto de Ciencias Ambientales y Evolutivas, Campus Isla Teja, Universidad Austral de

11 Chile, Valdivia, Chile

${ }^{4}$ ESPE de Paris, Université Sorbonne Paris IV, 10 rue Molitor, 75016 Paris, France

$14 *$ Author for correspondence

15 Jean-François Le Galliard

CNRS, UMR 7618, iEES Paris, Université Pierre et Marie Curie

7 Quai St Bernard, 75005 Paris, France

Tel: +33(0)1.44.27.26.68

Fax.: +33(0)1.44.27.35.16

E-mail: galliard@biologie.ens.fr

Running headline: Covariation between physiology and personality in lizards 
Covariation between physiology and personality in lizards

\section{ABSTRACT}

Stable differences in physiology among individuals may facilitate the evolution of consistent individual differences in behavior. In particular, according to the pace-of-life syndrome (POLS) hypothesis, individual variation in metabolic expenditure and stress physiology should be linked with exploration, aggression, or risk taking behaviors. Previous studies have uncovered stable individual differences in metabolic expenditure and circulating glucorticoids in common lizards (Zootoca vivipara). We tested for correlations between standard metabolic rates (SMR), glucorticoid stress response and behavioral traits (activity, aggressiveness, risk taking and sociability) in males. In ectotherms, the thermal dependence of SMR should be included in the POLS hypothesis; we therefore measured SMR at three temperatures from rest to preferred body temperature. Activity, aggressiveness and risk taking, but not sociability, exhibited significant, short term repeatability, and little correlation was found between behavioral traits. The SMR of lizards with a low metabolism at rest increased faster with body temperature. The SMR at rest was negatively correlated with behavioral variation in sociability and activity but not with risk taking behavior. In addition, the plasma corticosterone level after an acute, handling stress increased slightly but not significantly with aggressiveness. We discuss alternative interpretations for these relationships and conclude that the link between inter-individual variation in physiology and behavior is trait-dependent in the common lizard.

Keywords: locomotion, metabolism, corticosterone, temperament, personality, reptiles. 
Covariation between physiology and personality in lizards

\section{SIGNIFICANCE STATEMENT}

Selection better promotes the evolution of consistent differences in behavior, or personalities, when they are coupled with differences in physiology. In adult common lizards, interindividual differences in metabolic expenditure and glucocorticoid stress response are consistent and could play a crucial role in the maintenance of personalities. This study supported this hypothesis. We found that more sociable and active personality types had a lower metabolic expenditure, while more aggressive personality types tended to have a higher physiological stress response. At the same time, physiology was not correlated with individual differences in risk taking behavior and drove little part of behavioral variation. The coupling between personalities and physiology appears to be trait-dependent, suggesting that behaviors may be relatively free to evolve independently from physiology.

\section{INTRODUCTION}

The concept of "animal personality" refers to consistent inter-individual differences (CIDs) in behavior across time and/or contexts (Réale et al. 2007). Empirical evidence of CIDs in behavior are widespread in the animal kingdom (reviewed in Bell et al. 2009), and personality traits may play a crucial role in some ecological and evolutionary processes (Sih et al. 2004a; Réale et al. 2007; Dingemanse and Wolf 2010). Animal personalities are generally organized along a few major behavioral dimensions, including activity and exploration, risk taking, aggressiveness and sociability (Réale et al. 2007). Two or more of these dimensions may be associated with suites of correlated traits called behavioral syndromes (reviewed in Sih et al. 2004b), particularly the syndrome linking activity, exploration, risk taking and aggressiveness (Sih and Bell 2008). This syndrome, found in several species, is referred to as the shy-bold axis (Wilson et al. 1994) or the reactive-proactive continuum (Koolhaas et al. 1999).

A potential explanation for the occurrence of repeatable, consistent and correlated differences in behavior is that suites of behavioral traits may co-vary with stable differences in physiology (Biro and Stamps 2010; Coppens et al. 2010; Dingemanse and Wolf 2010). In 
particular, CIDs in behavior along the reactive-proactive continuum should be linked to the physiological stress response (i.e., stress-coping style hypothesis, Koolhaas et al. 1999, 2010; Øverli et al. 2007; Coppens et al. 2010). The reactive and proactive behavioral types are considered adaptations for life in unstable and stable environments, respectively; thus, shy and reactive individuals are characterized by higher levels of physiological stress responses than bold and proactive individuals (Cockrem 2007). In vertebrates, the physiological stress response involves activation of the hypothalamo-pituitary-adrenal (HPA) axis, where exposure to stress stimulated secretion of glucocorticoids (e.g., Cockrem 2007). In turn, glucocorticoid secretion elicits a cascade of physiological and behavioral processes that are essential to cope with stressful events (Wingfield and Ramenofsky 1999; Landys et al. 2006). The stress-coping style hypothesis makes the specific predictions that proactive and bold individuals should have lower baseline concentrations of glucocorticoids and a less reactive HPA axis. These predictions are well-supported by research with domestic and laboratorybred animals (Koolhaas et al. 1999; Groothuis and Carere 2005), especially lines selected for coping styles in mice (Veenema et al. 2003) and great tits (Carere et al. 2003; Baugh et al. 2012), but less by more recent field studies (Lendvai et al. 2011; Baugh et al. 2013). They have not yet been tested in squamate reptiles (lizards and snakes).

In addition, a link could exist between energy expenditure and behavior (Careau et al. 2008; Biro and Stamps 2010; Careau and Garland 2012) because energy acquisition and allocation constraints should influence behavioral traits involved in net energy gain (e.g., foraging) and/or those that are energetically costly (e.g., aggressiveness, see Mathot and Dingemanse 2015). In particular, the basal metabolic rate (BMR, a measure of the minimal energy expenditure in post-absorptive individuals at rest) is both repeatable and consistent through time (Nespolo and Franco 2007) and should be correlated with activity, risk taking, exploration and aggressiveness (Wolf and McNamara 2012). Two opposite scenarios have been proposed to explain the partition between BMR and the total energy expenditure (Careau 
et al. 2008; Mathot and Dingemanse 2015). The first states that higher total energy expenditure might imply investment in physiological processes and anatomical features that support higher productivity. In this case, we expect a higher BMR to correlate with bolder and/or more proactive behaviors (i.e., production model of bioenergetics, Careau et al. 2008;

Careau and Garland 2012). Examples include numerous studies of aggression, risk taking and exploration in fishes, mammals and a few bird species (e.g., Cutts et al. 2001; Mathot and Dingemanse 2015). In contrast, a negative relationship between BMR and proactivity is expected when the amount of energy spent in maintenance is unavailable to sustain net energy gain and energy is limited (i.e., allocation model of bioenergetics, Careau et al. 2008; Careau and Garland 2012). This prediction has received less support (Mathot and Dingemanse 2015), despite evidence that BMR may represent a cost to growth and survival (e.g., Steyermark 2002; Artacho and Nespolo 2009).

Energy metabolism, glucorticoid stress response and personality should thus be integrated into a general syndrome called the Pace Of Life Syndrome, or POLS (Ricklefs and Wikelski 2002; Careau et al. 2009; Réale et al. 2010; Le Galliard et al. 2013). However, intraindividual variation induced by thermal conditions (neglected thus far) might complicate the relationship between metabolic expenditure and behavior in ectothermic species (Artacho et al. 2013). For example, in previous studies, metabolic rates were obtained by repeated measurements at a single temperature. In ectotherms, the standard metabolic rate (SMR, a measure of BMR at a given temperature) significantly increases with body temperature, and the thermal dependence of SMR might differ markedly among individuals (Nespolo et al. 2003; Careau et al. 2014). Hence, energetic data in ectotherms should preferably be calculated from SMR obtained along a thermal gradient. For example, a recent study of the slimy salamander (Plethodon albagula) by Careau et al. (2014) found significant inter-individual variation in the thermal dependence of metabolism, in that the metabolic ranking of individuals changed with body temperature. Thus, additional data on ectotherms is needed in 
Covariation between physiology and personality in lizards

124

order to rigorously assess the relationship between personality traits and metabolism after taking into account intra-individual differences in metabolic thermal sensitivity.

To explore the links between personality traits, standard metabolic rates and the glucocorticoid stress response, we conducted two independent observational studies with male common lizards, Zootoca vivipara. In a first study, we measured covariation between personality traits and resting metabolic rates measured at three relevant body temperatures. In a second study, we tested for covariation between personality traits and individual plasmatic levels of corticosterone, quantified both in the field and in the laboratory after exposure to an acute stress. Rather than examining the correlation between physiology and a single personality trait (reviewed in Mathot and Dingemanse 2015), we measured several behavioral dimensions simultaneously, including activity, risk taking, sociability and aggressiveness. CIDs in behavior have been documented previously for activity, exploration, sociability and risk taking in juvenile common lizards (Cote and Clobert 2007; Le Galliard et al. 2013, 2015), and there is independent variation in activity, risk taking and sociability (Le Galliard et al. 2015). In adults, measurements of SMR are repeatable and consistent over short time periods (e.g., Artacho et al. 2013). The link between SMR and behavioral activity has been explored in juvenile lizards but no significant correlation was found (Le Galliard et al. 2013). However, by taking into account intra-individual variation in metabolism and several behavioral traits, we expect to gain greater insight into the relationship between behavioral syndromes and metabolism. In addition, plasma corticosterone levels of common lizards are repeatable over several days in the laboratory (SM \& J-FLG unpubl. data) and increased corticosterone secretion in response to a stressor modifies activity and foraging behaviors (de Fraipont et al. 2000; Cote et al. 2006). Whether this intra-individual variation parallels inter-individual variation along a general proactive-reactive continuum remains to be tested. 
Covariation between physiology and personality in lizards

\section{MATERIALS AND METHODS}

\section{Study species}

The common lizard (Zootoca vivipara) is a small viviparous lacertid (50-70mm adult snoutvent length) widely distributed in Eurasia. In our study populations at the Centre de Recherche en Ecologie Expérimentale et Prédictive, France (48¹7'N, $\left.2^{\circ} 41^{\prime} E\right)$, hibernation takes place from October to February-March for males, while females emerge a few weeks later in March-April. Mating season begins upon the emergence of females and lasts 2-4 weeks. The size of our semi-natural enclosures (each $100 \mathrm{~m}^{2}$ ) is similar to the area occupied by overlapping ranges of several lizards. Dispersal was prevented, lizards were protected from terrestrial and avian predators, and no food or water supplements were provided. Only male individuals were considered in this study so as to avoid interferences of gravidity on metabolic measurements and general sex differences in physiology and behavior. To minimize observer bias, blinded methods were used: the persons in charge of recording and analyzing behavioral data were not aware of the physiological scores of lizards, and different persons collected and processed behavioral and physiological data.

\section{Study 1: covariation between behavior and metabolism}

Thirty-nine adult males ( $n=7$ two-years old and $n=32$ more than two-years old) were captured in 2011 between May 16 and 19 from ten enclosures and measured for snout-vent length (SVL, range=53-63 cm, mean = 57.7) and body mass. Right after their capture, all lizards were placed in individual terraria (25 x 16 x 15 cm) and kept under standardized daynight (16h night: $8 \mathrm{~h}$ day) and temperature conditions $\left(16^{\circ} \mathrm{C}\right.$ night: $23^{\circ} \mathrm{C}$ day) with food and water ad libitum (see Le Galliard et al. 2003 for detailed protocols). Individuals were measured once for three behavioral traits, activity $(\mathrm{N}=29)$, boldness $(\mathrm{N}=30)$ and sociability $(\mathrm{N}=30)$ within eight days of capture. Then, from July 1 to July 10, the SMR was measured for each lizard at $15^{\circ} \mathrm{C}, 25^{\circ} \mathrm{C}$ and $35^{\circ} \mathrm{C}$ (see details below). These temperatures were chosen because they cover the range of variation of body temperatures experienced 
during different activities, including temperature at rest, preferred body temperature and an intermediate value (Le Galliard et al. 2003). We did not take repeated measurements of activity, boldness and sociability. However, short-term repeatability estimates were calculated at the same time from another sample of adult lizards maintained in the same conditions and tested twice for the same behaviors the same year. In the data set involving measurement of repeatability, behaviors were also recorded within eight days of recapture of individuals, and repeated measures were taken the same day a few hours apart.

\section{Study 2: covariation between behavior and stress response}

For this study, fifty adult males ( $n=13$ two-year-olds and $n=37$ older than two years) were captured on March 31, 2014 from 10 different enclosures and measured for SVL (range=48$62 \mathrm{~cm}$, mean $=57.5 \mathrm{~cm}$ ) and body mass. Blood samples were taken immediately following capture. In order to avoid biases due to capture and handling stress, we performed short visits to each enclosure (in general, less than $5 \mathrm{~min}$ ) and collected all blood samples within less than 3 min of capture. To account for potential stress due to our visits to the enclosures, we measured the time between each capture and the first visit for each lizard (hereafter called time spent in the enclosure). Lizards were then transferred into individual terraria and held under the same conditions as lizards experienced in study 1. Activity, boldness and aggressiveness were measured during a first series of behavioral tests starting on day 7. On day 7 , half of the lizards were tested for activity and aggressiveness, while the other half were measured for boldness and aggressiveness. On day 8, each group was tested for the behavior not measured during day 7 , and then fed with a standard quantity of live crickets to ensure similar digestive state before the next measurements. The second session started on day 9 and followed the same procedure as the first one to obtain repeated measures. At day 11, another blood sample was collected in order to assess the corticosterone stress response under laboratory conditions. To ensure that peak corticosterone levels were reached, lizards were exposed to handling and simulated predation stress by scaring them with a paint brush for 10 
Covariation between physiology and personality in lizards

minutes before blood sampling (Dauphin-Villemant and Xavier 1987). Plasma corticosterone levels were assessed using an immuno-enzymatic reaction following protocols previously used in (Meylan et al. 2003).

\section{Collection of behavioral data}

We used a neutral arena test to investigate exploratory behavior and locomotor activity (Le Galliard et al. 2013). All tests were done during the daily activity period between 10 am and 5 pm. Each lizard was placed in a plastic box $(44.5 \mathrm{~cm}$ x $24 \mathrm{~cm}$ x $26 \mathrm{~cm})$ maintained in a room at a standard temperature of $23-25^{\circ} \mathrm{C}$ with one heat source ( $40 \mathrm{~W}$ bulb) at the centre and two white light sources (Iguana Light 10.0 UV-B, ZooMed, $40 \mathrm{~W}$ ). The soil was covered with clean sand before each trial to avoid interference with odors from conspecifics. Each lizard was placed in the plastic box for a 10 min acclimation period, and then filmed from above for 30 min with a webcam (Hercules Deluxe). The film was downloaded using Virtual Dub 1.7.8 and image sequence from each video was obtained (one frame per second). From these videos, we recorded lizard position (x-y coordinates) in ImageJ v1.40 (http://rsbweb.nih.gov/ij/) using a particle analysis procedure (Mallard et al. 2013). We calculated the percentage of time spent walking and the travel distance during each trial. For study 2, we also calculated the total time spent basking and the total time spent scratching the wall with real-time recordings of behaviors.

We measured risk-taking (or boldness) behavior based on the behavior of a lizard after a simulated attack by a human (e.g., López et al. 2005; Le Galliard et al. 2015). Plastic boxes were equipped with a cardboard shelter on one corner to provide a refuge and with a heat source on the opposite corner to provide a stimulus for basking. After the acclimation period, we simulated several consecutive predator attacks with a paintbrush, softly touching the tail to force the lizard into the shelter. If the lizard was already inside the shelter, we simulated attacks around the shelter to force the head of the lizard into the shelter. We then filmed the behavior from above and calculated the time spent hiding (body and head inside the refuge) 
before leaning out of the refuge (body inside the refuge but tip of the nose emerging from the shelter), the time spent before emerging from the refuge (body and head outside the refuge), and the time spent before basking under the heat source on the opposite side of the box. Recordings stopped after 60 min. This procedure allowed for "censoring" of boldness scores for one lizard in each study (i.e., less than $3 \%$ of recordings). We replaced boldness scores by the maximum value (3,600 secs) for these animals.

We quantified sociability by scoring the preference of lizards for odors of adult males during a simultaneous choice test of 20 min (Le Galliard et al. 2015). Two identical plastic shelters were placed on each side of the terrarium. We put a piece of absorbent paper impregnated with the odor of adult males under one shelter and a piece of odorless paper under the other shelter. Lizards were filmed from above and two indices of sociability were measured: an absolute index calculated as the difference between time spent in the shelter with the odor and time under the shelter without the odor scaled to the total duration of the test, and a relative index, where time difference was divided by the total time spent hidden (Cote and Clobert 2007; Cote et al. 2008; Le Galliard et al. 2015). In each study, odors were obtained from four groups of 3 randomly chosen adult males after a minimum period of six days. Odorless papers were collected from a cage without lizards located in the same room. We measured aggressiveness in response to capture and handling when we removed the lizards from the exploration and risk taking tests. One experimenter grabbed the lizard in his hand and held it in front of himself until it was relatively immobile. The experimenter then touched the tip of the nose with the side of his finger four times in order to elicit aggressive reactions and counted the total number of biting attempts. The score thus ranged from 0 (no bite) to 4, and scores are reported as "aggressiveness after exploration” and "aggressiveness after risk taking” depending upon the behavioral test preceding the measurement.

\section{Measurement of metabolic rate}

The standard metabolic rate (SMR) is defined as the minimum rate of energy expenditure 
under post-absorptive conditions in a resting phase at dark and at a given temperature within the animal's range of activity (Andrews and Pough 1985). Metabolic rates were estimated with a multiple-channel flow-through respirometry system (Qubit Systems, Canada) coupled with a differential $\mathrm{O}_{2}$ analyzer (DOX; S104 Differential Oxygen Analyzer) and a $\mathrm{CO}_{2}$ analyzer (S157) connected to respirometry software (QS Research). Metabolic records were processed by a macro program recorded in ExpeData software (Sable Systems) to transform the measurements from parts per million to milliliters per hour, taking into account the flow rate $(140 \mathrm{~mL} / \mathrm{min})$. SMR was measured once at each of three body temperatures $\left(15^{\circ} \mathrm{C}\right.$ : minimum temperature, $25^{\circ} \mathrm{C}$ : intermediate body temperature during activity and $35^{\circ} \mathrm{C}$ : inside the range of preferred body temperature) after a fasting period of 72 hours to ensure postabsorption conditions. Individuals were placed in a room at a constant temperature of $15^{\circ} \mathrm{C}$ the night before recording, and were kept in the dark until being weighted and placed in the measurement chamber for an hour of acclimation at the test temperature. Excurrent $\mathrm{O}_{2}$ and $\mathrm{CO}_{2}$ concentrations were then measured continuously for 45 minutes at the same temperature. The average respiratory quotient of the population, calculated from the production of $\mathrm{CO}_{2}$ and consumption of $\mathrm{O}_{2}$ obtained from all individuals, was then used to convert the values of $\mathrm{CO}_{2}$ production (mL/h), averaged over the recording, into energy expenditure $(\mathrm{J} / \mathrm{h})$.

\section{Statistical analyses}

All statistical analyses were carried out in R 3.0.3 (https://www.r-project.org/). Repeated measurements of the three focal behaviors, activity, risk taking and aggressiveness, were analyzed with linear mixed-effects models (LMM) using the lme function (Pinheiro and Bates 2000). The LMM fitted to each behavioral variable included a fixed time effect to control for changes in behavior across repeated measures and a random individual effect. From this, we assessed the significance of random effects with likelihood ratio tests (LRT) and calculated a repeatability coefficient as the intra-class correlation coefficient (Wolak et al. 2012), which equals to the ratio of between-individual variance to total (between-individual and residual) 
278

279

280

281

282

283

284

285

286

287

variance. Since the between-individual variance can take only positive values, the $\chi^{2}$ statistics of the LRT is distributed as an equally weighted mixture of $\chi^{2}$ distributions with one and zero degrees of freedom (Careau et al. 2014 and references therein). Thus, we halved the P-values obtained from the standard $\chi^{2}$ distribution with one degree of freedom (equivalent to $\chi_{0: 1}^{2}$ in results below). In addition, behavioral syndromes were explored using principal component analyses (PCAs) of the mean, individual values of each behavioral trait. PCAs were implemented with the function dudi.pca in the R package ade4 using a correlation matrix implicitly rescaling all variables (Chessel et al. 2004). The number of principal components retained for the analysis was determined on the basis of the broken-stick method (Legendre and Legendre 1998). We identified statistically significant contributions to the different PCs by calculating the inertia attributed to each variable. The contribution of the variable was considered significant when its inertia was greater than the mean inertia.

We analyzed the thermal sensitivity of SMR using individual linear regressions computed to calculate an intercept score (SMR value predicted at $15^{\circ} \mathrm{C}$ ) and an intercept slope score (SMR thermal sensitivity) for each individual. We also calculated the thermal repeatability of SMR (Nespolo et al. 2003; Careau et al. 2014) by running a linear mixedeffects model. This model included a fixed effect of body temperature and random variation among individuals for the mean SMR across the thermal gradient. To obtain the thermal repeatability $\left(\mathrm{R}_{\mathrm{T}}\right)$, we used the variance components (residual and between-individual variation) and calculated the ratio of between-individual to total variation. We tested the significance of the random inter-individual based on a LRT (see above). The SMR data were log-transformed prior to the analyses, which resulted in a better statistical distribution of the residuals and improved linearity of effects.

We used the PC scores obtained from the PCAs described above to explore the covariation between behavioral traits and physiology (SMR and plasma corticosterone levels). For SMR, we fitted a linear model with the SMR as a dependent variable and the individual 
scores for each PC, age class, and body mass as fixed-effect independent variables. For plasma corticosterone, field levels were analyzed with a linear model including fixed effects of age, SVL, and individual scores for each PC as well as time spent in the enclosure before capture. Laboratory stress-induced corticosterone levels were analyzed with the same model including the basal plasma corticosterone levels as a covariate to control for differences in basal secretion of corticosterone prior to handling stress. In all cases, model assumptions (normality and homogeneity of variance of the residuals) were fulfilled and the best model was chosen by a stepwise selection procedure based on AIC (Burnham and Anderson 1998). Several individuals came from the same enclosures in both studies but addition of a random effect of enclosure identity did not change the conclusions of our statistical analyses since there was very little variation among enclosures (all $p>0.08$, results not shown). We report the mean and standard error of mean of estimates unless otherwise stated.

\section{RESULTS}

\section{Consistent individual differences in behavior}

We found consistent individual differences for most behavioral variables, except for time with head hidden during study 2 and for sociability scores and time spent walking in study 1 (Table 1). The PCAs suggested different patterns of behavioral covariation in the two studies (Table 2). In study 1 , we retained three major axis explaining $85 \%$ of the total variance. The first principal component (PC1) loaded significantly with two variables measuring risk taking, while variables related to sociability (and to some extent activity) showed a strong positive correlation with PC2. PC3 was positively correlated with variables measuring activity and one boldness score. Thus, PC1 measured variation in risk taking and PC2 score indicated variation in sociability, while PC3 scored activity and exploration. In study 2, we retained three major axes explaining $81 \%$ of the variance. PC1 was positively correlated to variables related to activity and negatively correlated to risk taking. PC2 was negatively correlated to mobility and risk taking but positively correlated to basking time. PC3 loaded only significantly with 
Covariation between physiology and personality in lizards

the variables related to aggressiveness.

The removal of one outlier for boldness scores in study 1 influenced the correlation pattern represented by PC2 and PC3 (Table S1 provided as supplementary information). Without the outlier, the second principal component (PC2) was positively related to activity and sociability, while PC3 had a strong negative correlation with variables measuring activity but was positively correlated with sociability. Thus, PC2 score indicated variation in both activity and sociability (and not only sociability like in Table 2), while PC3 made the contrast between more sociable but less active lizards from less sociable and more active lizards.

\section{Covariation between metabolism and personality}

The SMR increased significantly and almost linearly with body temperature on the log scale (mixed-effects model, body temperature effect: slope $=0.10 \pm 0.0048, \mathrm{~F}_{1,79}=437.1, p<$ 0.001; Fig. 1A). According to individual regressions, slopes (log SMR, mean $=0.10 \pm 0.009$ $\mathrm{SD})$ and intercepts at $15^{\circ} \mathrm{C}(\log \mathrm{SMR}$, mean $=1.65 \pm 0.47 \mathrm{SD})$ were strongly negatively correlated (Pearson moment-correlation : $r=-0.85, p<0.0001$ ). Given this pattern of crossing thermal sensitivity curves (Fig. 1A), the thermal repeatability of SMR was small $\left(\mathrm{R}_{\mathrm{T}}\right.$ $=0.052)$ and not significant $\left(\chi_{0: 1}^{2}=0.30, p=0.27\right)$. The best model (adjusted $\mathrm{R}^{2}=0.126$ ) describing metabolic variation (intercept at $15^{\circ} \mathrm{C}$ ) included the PC2 score measuring variation in sociability (slope $=-0.103 \pm 0.05, \mathrm{~F}_{1,36}=4.21, p=0.047$, Fig. $1 \mathrm{~B}$ ) and a marginal negative effect of PC1 score (slope $=-0.08 \pm 0.04, \mathrm{~F}_{1,36}=3.30, p=0.077$ ). This effect of PC1 did not hold when we removed one outlier for boldness score (Table S2).

\section{Covariation between glucorticoid stress response and personality}

Mean plasma corticosterone levels were higher in the field than after exposure to a handling stress in the laboratory (mean level in the field: $56.3 \mathrm{ng} / \mathrm{mL} \pm 2.33$, range: 21.4-92.8; mean stress-induced level: $35.0 \pm 2.66$, range: 6.98-117.6, paired t-test: $t_{49}=7.35, p<0.001$; Fig. 2A). We found no significant effects of behavioral score, SVL, time spent in the enclosure and age class on plasma corticosterone concentration in the field (all $p>0.21$ ). The best 
Covariation between physiology and personality in lizards

model (adjusted $\mathrm{R}^{2}=0.16$ ) selected to describe variation in stress-induced corticosterone levels in the laboratory included two variables, a positive effect of field corticosterone (slope $\left.=0.41 \pm 0.15 \mathrm{SE}, \mathrm{F}_{1,47}=6.32, \mathrm{p}=0.015\right)$ and a marginal, negative effect of PC3 score, which is positively correlated to aggressiveness (slope $=3.60 \pm 1.92 \mathrm{SE}, \mathrm{F}_{1,47}=3.49, p=0.068$, Fig. 2B). The removal of one "outlier" for corticosterone titer (Fig. 2A) weakened the effect of PC3 (slope $=2.69 \pm 1.60 \mathrm{SE}, \mathrm{F}_{1,46}=2.85, p=0.099$, Fig. $2 \mathrm{~B}$ ), as well as the correlation between field corticosterone and the stress response (slope $=0.21 \pm 0.13 \mathrm{SE}, \mathrm{F}_{1,46}=1.94, p=$ 0.17, Fig. 2A).

\section{DISCUSSION}

In male common lizards, behavioral traits describing variation in activity, aggressiveness and risk-taking exhibited significant, short-term repeatability, while behavioral traits describing sociability did not. These results agree with previous findings of consistent individual differences in behavior in juveniles (Cote and Clobert 2007; Le Galliard et al. 2013, 2015). However, they are contradictory to those of earlier studies, where sociability was consistent on the short-term in juveniles (Le Galliard et al. 2015). Differences in short-term consistency of sociability between adults and juveniles are not just a consequence of a small and relatively homogeneous data set of adult males in this study, because it was confirmed in a longitudinal study including both sexes and more age classes (HM \& J-FLG, unpubl. data). The higher consistency of sociability in juveniles than in older individuals may be due to a more pronounced sensitivity to odors of adult males in juveniles than in adults, and/or changes in the ecological relevance of the test with age (Bell et al. 2009). For example, sociability is involved in dispersal behavior and consistently associated with the natal dispersal type in juveniles but may be of limited relevance in adults, since this age class disperses less (Le Galliard et al. 2005). The use of a shelter choice experiment in adults may also be problematic since adult males tend to prioritize direct social interactions and are bolder and less attracted to the shelter than juveniles (J-FLG pers. obs.). 
Covariation between physiology and personality in lizards

The principal component analyses highlighted relatively weak and non-significant associations between most personality traits. Yet, there was evidence of a positive association between activity and risk taking in study 2 for PC1. In study 1, the association between activity and risk taking for PC1 was in the same direction but was not significant based on the inertia criterion. Activity was also associated positively with sociability in study 1 . Behavioral syndromes have been little investigated so far in squamate reptiles relative to other taxa.

Similar to our results, a behavioral syndrome linking independent measures of activity, boldness, sociability and/or aggression was not found in juvenile common lizards (Le Galliard et al. 2015) and in adult White's skinks (McEvoy et al. 2015). Rodriguez-Prieto et al. (2011) also suggested that exploration, sociability and boldness represent three independent facets of the personality of adult Iberian wall lizards (but see Stapley and Keogh 2004). Considering these results with our own could indicate that behavioral syndromes are not organized in squamate reptiles as they are in other vertebrate taxa. However, it could be that we lacked statistical power to detect small but meaningful correlations among traits. Larger sample sizes (here, $\mathrm{N}<50$ ) and more repeated measurements (here, 1 to 2 ) may be needed to score personality when traits are poorly repeatable (here, $0.14<r<0.70$ ) and to obtain unbiased estimates of correlations (reviewed in Garamszegi et al. 2012).

Regarding the individual variation in the standard metabolic rate (SMR), we found variation among individuals at the lowest body temperature (intercept), in addition to showing that lizards with a low intercept had a greater increase of their SMR with body temperature. Although these results must be considered with some caution, as we only tested animals once at each temperature, they suggest crossing thermal sensitivity curves for SMR (Careau et al. 2014). This could indicate that lizards that minimize basal energy expenditure at rest (low body temperatures) have higher basal expenditures at activity (high body temperatures). The robustness and generality of this pattern remains to be tested in larger samples of common 
lizards and in other species, and with several repeated measures at each temperature. In addition, we found that individuals with high values of sociability, and to some extent activity, were characterized by a lower SMR at $15^{\circ} \mathrm{C}$.

At first glance, the negative relationship obtained between the SMR at $15^{\circ} \mathrm{C}$ and the sociability-activity axis seems to support the allocation model of energy management, where SMR constrains the expression of energetically costly behaviors (Careau et al. 2008; Careau and Garland 2012; Mathot and Dingemanse 2015). However, a more detailed examination of the results cautions against such a straightforward explanation. First, PC1 and PC3 scores directly related to risk taking and activity were not correlated with SMR even though these may reflect variation in energetically costly behaviors (Mathot and Dingemanse 2015).

Second, even after accounting for the effect of PC2 score, much variation in SMR remained. Third, despite good evidence that SMR represents a significant part of total energy expenditure in lizards (e.g., Niewiarowski and Waldschmidt 1992), no empirical study has yet examined among-individual partitioning of energy into maintenance, activity and other energetic expenses. Given that an increased SMR does not seem to impair mean growth, survival or reproduction in this species (Le Galliard et al. 2013; Artacho et al. 2015), we cannot tell with certainty that differences in SMR represent a significant energetic constraint at the individual level. Fourth, our study indicates that conclusions from correlation patterns between behavior and physiology obtained with measures of SMR at one body temperature may be misleading. Since low SMR at $15^{\circ} \mathrm{C}$ was strongly, negatively associated with the thermal sensitivity of RMR, more sociable and active lizards did not necessarily have the lowest SMR at the highest body temperatures. Thus, when thermal repeatability of RMR is low, correlative studies linking animal personality and energetics may lead to results supporting the allocation model, the performance model or none of them, depending on temperature used during measurements. While estimates of SMR at one body temperature are generally repeatable over time (Nespolo and Franco 2007), the thermal repeatability of SMR 
Covariation between physiology and personality in lizards

can be low when individuals vary in the thermal sensitivity of their metabolism (Careau et al. 2014). This suggests that relevant aspects of thermal biology should be considered when examining behavioral and physiological syndromes in ectotherms. In particular, we advocate for future investigations of covariation patterns between behaviors and physiology by repeatedly measuring all traits at several body temperatures.

The plasmatic levels of corticosterone varied significantly among individuals, as was found in previous studies (Meylan et al. 2003; Fitze et al. 2009). Field plasmatic levels of corticosterone were positively correlated with, but also higher than, the stress-induced levels measured in the laboratory. This surprising difference could be due to elevated levels of corticosterone needed to sustain the locomotor activity and mating behavior of adult males in the field. In addition, the stress induced by confinement in the laboratory does not last more than a day in the common lizard (Dauphin-Villemant and Xavier 1987) and lizards might have returned to low basal levels before we started the handling stress measurements.

Unfortunately, we did not measure basal levels in the laboratory prior to handling stress. The plasmatic level of corticosterone after exposure to a handling stress in the laboratory, corrected for basal variation in corticosterone levels from the field, was weakly and almost significantly positively correlated with aggressiveness. This link was tenuous and did not hold when we removed one extreme data point.

These results contradict the hypothesis that the glucocorticoid stress response constitutes a causal proximate mechanism behind the activity-aggressiveness-risk taking behavioral syndrome, since we found no correlation with activity and boldness. In addition, the weak correlation found for aggressiveness, if real, contrasts with findings in some bird and mammal species, where more aggressive individuals have a lower HPA axis activity and reactivity in response to a stressor (i.e., proactive coping style, Koolhaas et al. 1999; Groothuis and Carere 2005; Cockrem 2007). For example, house mice selected for low 
Covariation between physiology and personality in lizards

460

461

462

463

464

465

466

467

468

469

470

471

472

473

474

475

476

477

478

479

480

481

482

483

484

485

aggression have higher basal corticosterone levels during daytime and prolonged

corticosterone secretion in response to a strong stressor (Veenema et al. 2003). Similarly, great tits (Parus major) selected for slow exploration speed are less aggressive and have more elevated corticosterone in response to a social stress than birds selected for fast exploration (Carere et al. 2003; Groothuis and Carere 2005; Baugh et al. 2012). The short-term increase of corticosterone concentration in response to a stressor also differs among individual birds, with stronger increase in slow than in fast explorers in Parus major and Passer domesticus (Lendvai et al. 2011; Baugh et al. 2013).

There is also some evidence of a positive correlation between measures of risk taking and/or exploration and reactivity of the HPA axis in zebra finches (Martins et al. 2007) and in domestic leghorns (reviewed in Groothuis and Carere 2005). Similar to the trend we found, this suggests that reactive coping at the physiological level may not be systematically coupled with a less aggressive, bold and exploratory behavioral type. In the only study to date on behavioral coping in lizards, Rodriguez-Prieto et al. (2011) found that more exploratory lizards habituated faster to a novel stress, and thus were more "reactive" because they acquired better and faster information about their environment. Additional data on behavioral coping styles are needed to confirm that this represents a general pattern in lizards.

Overall, our study uncovered some (albeit weaker than expected) relationships between behavior and physiology that we expected under the Pace Of Life Syndrome hypothesis, which states that behavioral syndromes are generally associated with physiological syndromes of the pace-of-life. The SMR at rest (measured at the lowest body temperature) was negatively correlated with behavioral variation in sociability and activity, and the plasma corticosterone level after an acute, handling stress increased slightly but not significantly with aggressiveness. Thus, correlations between physiology and behavior were trait-dependent and less consistent than predicted. In addition, even though we had reasonable sample size in this 
study, the observed correlations should be treated with some caution, because behavioral traits most likely to be correlated with physiology were not observed, correlations between behavior and physiology could be sensitive to a few extreme values, and the ranking of individual scores of metabolic expenditure was temperature-dependent. This suggests that stress physiology and metabolism drove only a small part of the inter-individual variation in behavior in the common lizard.

\section{COMPLIANCE WITH ETHICAL STANDARDS}

Acknowledgments: We thank Léna Baraud for her calculations of metabolic rate data, Samuel Perret and Julia Saravia for her assistance in the laboratory, and Claudy Haussy for assistance with hormonal assays. Gabrielle Names kindly corrected an earlier version of this manuscript. This research was supported by the Centre National de la Recherche Scientifique (CNRS), an Agence Nationale de la Recherche grant (ANR-13-JSV7-0011-01) to SM and a post-doctoral grant from Becas Chile to PA.

Authors contributions: J-FLG, PA, SM and RJ designed the study. All authors contributed data collection and HM analyzed the data. HM and J-FLG wrote the first draft, and all authors contributed to the writing.

Conflict of Interest: Authors declare no conflict of interest.

Ethical approval: All applicable international, national, and/or institutional guidelines for the care and use of animals were followed. Experiments were conducted under agreement A77341-1 delivered by the Préfecture de Seine-et-Marne. Animals were captured and manipulated under authorization 2007-198-005 delivered by the Prefecture de Seine-et-Marne.

\section{REFERENCES}

Andrews RM, Pough FH (1985) Metabolism of squamate reptiles - allometric and ecological relationships. Physiol Zool 58:214-231

Artacho P, Nespolo RF (2009) Natural selection reduces energy metabolism in the garden snail, Helix aspersa (Cornu aspersum). Evolution 63:1044-1050 
Artacho P, Jouanneau I, Le Galliard J-F (2013) Interindividual variation in thermal sensitivity of maximal sprint speed, thermal behavior, and resting metabolic rate in a lizard. Physiol Biochem Zool 86:458-469

Artacho P, Saravia J, Ferrandière BD, Perret S, Le Galliard J-F (2015) Quantification of correlational selection on thermal physiology, thermoregulatory behavior, and energy metabolism in lizards. Ecol Evol 5:3600-3609

Baugh AT, van Oers K, Naguib M, Hau M (2013) Initial reactivity and magnitude of the acute stress response associated with personality in wild great tits (Parus major). Gen Comp Endocrinol 189:96-104

Baugh AT, Schaper SV, Hau M, Cockrem JF, de Goede P, van Oers K (2012) Corticosterone responses differ between lines of great tits (Parus major) selected for divergent personalities. Gen Comp Endocrinol 175:488-494

Bell AM, Hankison SJ, Laskowski KL (2009) The repeatability of behaviour: a meta-analysis. Anim Behav 77:771-783

Biro PA, Stamps JA (2010) Do consistent individual differences in metabolic rate promote consistent individual differences in behavior? Trends Ecol Evol 25:653-659

Burnham KP, Anderson DR (1998) Model selection and inference: a practical informationtheoretical approach. Springer Verlag, New York

Careau V, Bininda-Emonds ORP, Thomas DW, Réale D, Humphries MM (2009) Exploration strategies map along fast-slow metabolic and life-history continua in muroid rodents. Funct Ecol 23:150-156

Careau V, Garland TJ (2012) Performance, personality and energetics: correlation, causation and mechanism? Physiol Biochem Zool 85:543-571

Careau V, Gifford ME, Biro PA (2014) Individual (co)variation in thermal reaction norms of standard and maximal metabolic rates in wild-caught slimy salamanders. Funct Ecol 28:1175-1186 
Careau V, Thomas D, Humphries MM, Réale D (2008) Energy metabolism and animal personality. Oikos 117:641-653

Carere C, Groothuis TGG, Möstl E, Daan S, Koolhaas JM (2003) Fecal corticosteroids in a territorial bird selected for different personalities: daily rhythm and the response to social stress. Horm Behav 43:540-548

Chessel D, Dufour A-B, Thioulouse J (2004) The ade4 package - I - One-table methods. R News 4:5-10

Cockrem J (2007) Stress, corticosterone responses and avian personalities. J Ornithol 148:169-178

Coppens CM, de Boer SF, Koolhaas JM (2010) Coping styles and behavioural flexibility: towards underlying mechanisms. Philos T Roy Soc B 365:4021-4028

Cote J, Clobert J (2007) Social personalities influence natal dispersal in a lizard. Proc R Soc Lond B 274:383-390

Cote J, Clobert J, Meylan S, Fitze PS (2006) Experimental enhancement of corticosterone levels positively affects subsequent male survival. Horm Behav 49:320-327

Cote J, Dreiss A, Clobert J (2008) Social personality trait and fitness. Proc R Soc Lond B 275:2851-2858

Cutts CJ, Adams CE, Campbell A (2001) Stability of physiological and behavioural determinants of performance in Arctic char (Salvelinus alpinus). Can J Fish Aquat Sci 58:961-968

Dauphin-Villemant C, Xavier F (1987) Nycthemeral variations of plasma corticosteroids in captive female Lacerta vivipara Jacquin: influence of stress and reproductive state. Gen Comp Endocrinol 67:292-302

de Fraipont M, Clobert J, John-Alder H, Meylan S (2000) Increased pre-natal maternal corticosterone promotes philopatry of offspring in common lizards Lacerta vivipara. J Anim Ecol 69:404-413 
Covariation between physiology and personality in lizards

564

565

566

567

568

569

570

571

572

573

574

575

576

577

578

579

580

581

582

583

584

585

586

587

588

589

Dingemanse NJ, Wolf M (2010) Recent models for adaptive personality differences: a review. Philos T Roy Soc B 365:3947-3958

Fitze PS, Cote J, San-Jose LM, Meylan S, Isaksson C, Andersson S, Rossi J-M, Clobert J (2009) Carotenoid-based colours reflect the stress response in the common lizard. PLoS ONE 4:e5111

Garamszegi LZ, Gábor M, Herczeg G (2012) A meta-analysis of correlated behaviours with implications for behavioural syndromes: mean effect size, publication bias, phylogenetic effects and the role of mediator variables. Evol Ecol 26:1213-1235

Groothuis TGG, Carere C (2005) Avian personalities: characterization and epigenesis. Neurosci Biobehav R 29:137-150

Koolhaas JM, de Boer SF, Coppens CM, Buwalda B (2010) Neuroendocrinology of coping styles: Towards understanding the biology of individual variation. Front Neuroendocrin $31: 307-321$

Koolhaas JM, Korte SM, de Boer SF, van der Vegt BJ, van Reenen CG, Hopster H, de Jong IC, Ruis MAW, Blokhuis HJ (1999) Coping styles in animals: current status in behavior and stress physiology. Neurosci Biobehav R 23:925-935

Landys MM, Ramenofsky M, Wingfield J (2006) Actions of glucocorticoids at a seasonal baseline as compared to stress-related levels in the regulation of periodic life processes. Gen Comp Endocrinol 148:132-149

Le Galliard J-F, Ferrière R, Clobert J (2005) Effect of patch occupancy on immigration in the common lizard. J Anim Ecol 74:241-249

Le Galliard J-F, Le Bris M, Clobert J (2003) Timing of locomotor impairment and shift in thermal preferences during gravidity in a viviparous lizard. Funct Ecol 17:877-885

Le Galliard J-F, Paquet M, Cisel M, Montes-Poloni L (2013) Personality and the pace-of-life syndrome: variation and selection on activity, metabolism and locomotor performances. Funct Ecol 27:136-144 
Covariation between physiology and personality in lizards

Le Galliard JF, Paquet M, Mugabo M (2015) An experimental test of density-dependent selection on temperament traits of activity, boldness and sociability. J Evol Biol 28:1144-1155

Legendre P, Legendre L (1998) Numerical ecology. Developments in environmental modelling, vol 20. Elsevier Science, Amsterdam

Lendvai AZ, Bókony V, Chastel O (2011) Coping with novelty and stress in free-living house sparrows. J Exp Biol 214:821-828

López P, Hawlena D, Polo V, Amo L, Martín J (2005) Sources of individual shy-bold variations in antipredator behaviour of male Iberian rock lizards. Anim Behav 69:1-9

Mallard F, Le Bourlot V, Tully T (2013) An automated image analysis system to measure and count organisms in laboratory microcosms. PLoS ONE 8:e64387

Martins TL, Roberts ML, Giblin I, Huxham R, Evans MR (2007) Speed of exploration and risk-taking behavior are linked to corticosterone titres in zebra finches. Horm Behav $52: 445-453$

Mathot KJ, Dingemanse NJ (2015) Energetics and behavior: unrequited needs and new directions. Trends Ecol Evol 30:199-206

McEvoy J, While GM, Sinn DL, Carver S, Wapstra E (2015) Behavioural syndromes and structural and temporal consistency of behavioural traits in a social lizard. J Zool 296:58-66

Meylan S, Dufty AJ, Clobert J (2003) The effect of transdermal corticosterone application on plasma corticosterone levels in pregnant Lacerta vivipara. Comp Biochem Phys A 134:497-503

Nespolo RF, Franco M (2007) Whole-animal metabolic rate is a repeatable trait: a metaanalysis. J Exp Biol 210:2000-2005 
614 Nespolo RF, Lardies MA, Bozinovic F (2003) Intrapopulational variation in the standard

615

616

617

618

619

620

621

622

623

624

625

626

627

628

629

630

631

632

633

634

635

636

637

638 metabolic rate of insects: repeatability, thermal dependence and sensitivity (Q10) of oxygen consumption in a cricket. J Exp Biol 206:4309-4315

Niewiarowski PH, Waldschmidt SR (1992) Variation in metabolic rates of a lizard: use of SMR in ecological contexts. Funct Ecol 6:15-22

Øverli Ø, SÃ,rensen C, Pulman KGT, Pottinger TG, Korzan W, Summers CH, Nilsson GE (2007) Evolutionary background for stress-coping styles: Relationships between physiological, behavioral, and cognitive traits in non-mammalian vertebrates. Neurosci Biobehav R 31:396-412

Pinheiro JC, Bates DM (2000) Mixed-effect models in S and S-plus. Statistics and Computing. Springer, New York

Réale D, Garant D, Humphries MM, Bergeron P, Careau V, Montiglio PO (2010) Personality and the emergence of the pace-of-life syndrome concept at the population level. Philos T Roy Soc B 365:4051-4063

Réale D, Reader SM, Sol D, McDougall PT, Dingemanse NJ (2007) Integrating animal temperament within ecology and evolution. Biol Rev 82:291-318

Ricklefs RE, Wikelski M (2002) The physiology/life-history nexus. Trends Ecol Evol 17:462468

Rodriguez-Prieto I, Martin J, Fernandez-Juricic E (2011) Individual variation in behavioural plasticity: direct and indirect effects of boldness, exploration and sociability on habituation to predators in lizards. Proc R Soc Lond B 278:266-273

Sih A, Bell AM (2008) Insights for behavioral ecology from behavioral syndromes. Adv Stud Behav 38:227-281

Sih A, Bell A, Johnson JC (2004a) Behavioral syndromes: an ecological and evolutionary overview. Trends Ecol Evol 19:372-377 
639

640

641

642

643

644

645

646

647

648

649

650

651

652

653

654

655

656

657

658

Sih A, Bell AM, Johnson JC, Ziemba RE (2004b) Behavioral syndromes: An integrative overview. Q Rev Biol 79:241-277

Stapley J, Keogh JS (2004) Exploratory and antipredator behaviours differ between territorial and nonterritorial male lizards. Anim Behav 68:841-846

Steyermark AC (2002) A high standard metabolic rate constrains juvenile growth. Zoology $105: 147-151$

Veenema AH, Meijer OC, de Kloet ER, Koolhaas JM, Bohus BG (2003) Differences in basal and stress-induced HPA regulation of wild house mice selected for high and low aggression. Horm Behav 43:197-204

Wilson DS, Clark AB, Coleman K, Dearstyne T (1994) Shyness and boldness in humans and other animals. Trends Ecol Evol 9:442-446

Wingfield JC, Ramenofsky M (1999) Hormones and the behavioral ecology of stress. In: Palm PHM (ed) Stress physiology in animals. Biological Sciences Series. Sheffield Academic Press, Sheffield, pp 1-51

Wolak ME, Fairbairn DJ, Paulsen YR (2012) Guidelines for estimating repeatability. Methods Ecol Evol 3:129-137

Wolf M, McNamara JM (2012) On the evolution of personalities via frequency-dependent selection. Am Nat 179:679-692 
Covariation between physiology and personality in lizards

TABLES

660

Table 1 Repeatability estimates (REP), likelihood ratio test (LRT) statistics and associated p-

values computed to assess the significance of the random, inter-individual variance for each

behavioral trait in the first and second studies. Significant REP values are shown in bold

\begin{tabular}{|c|c|c|c|c|c|}
\hline & & \multicolumn{2}{|c|}{ Study 1 of personality } & \multicolumn{2}{|c|}{ Study 2 of personality } \\
\hline & Behavior & LRT & REP & LRT & REP \\
\hline \multirow{4}{*}{ 总 } & Movement distance & $\chi_{0: 1}^{2}=4.49, \mathrm{p}=0.017$ & 0.48 & $\chi_{0: 1}^{2}=15.4, \mathrm{p}<0.0001$ & 0.51 \\
\hline & Time spent walking & $\chi_{0: 1}^{2}=0.29, p=0.29$ & 0.27 & $\chi_{0: 1}^{2}=20.9, \mathrm{p}<0.0001$ & 0.58 \\
\hline & Time spent scratching & l & / & $\chi_{0: 1}^{2}=25.2, \mathrm{p}<0.0001$ & 0.71 \\
\hline & Time spent basking & l & l & $\chi_{0: 1}^{2}=35.3, \mathrm{p}<0.0001$ & 0.63 \\
\hline \multirow{3}{*}{  } & Time head hidden & $\chi_{0: 1}^{2}=17.3, \mathrm{p}<0.0001$ & 0.52 & $\chi_{0: 1}^{2}=0.97, \mathrm{p}=0.32$ & 0.14 \\
\hline & Time body hidden & $\chi_{0: 1}^{2}=3.69, \mathrm{p}=0.027$ & 0.45 & $\chi_{0: 1}^{2}=19.0, \mathrm{p}<0.0001$ & 0.56 \\
\hline & Time until basking & $\chi_{0: 1}^{2}=2.95, \mathrm{p}=0.043$ & 0.43 & $\chi_{0: 1}^{2}=20.9, \mathrm{p}<0.0001$ & 0.58 \\
\hline \multirow{2}{*}{ 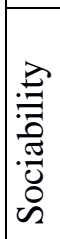 } & Absolute sociability score & $\chi_{0: 1}^{2}=0.94, p=0.17$ & 0.34 & / & / \\
\hline & Relative sociability score & $\chi_{0: 1}^{2}=0.20, p=0.32$ & 0.25 & / & l \\
\hline \multirow{2}{*}{ 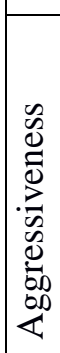 } & $\begin{array}{l}\text { Aggressiveness after } \\
\text { exploration }\end{array}$ & l & l & $\chi_{0: 1}^{2}=17.5, \mathrm{p}<0.0001$ & 0.54 \\
\hline & $\begin{array}{l}\text { Aggressiveness after risk } \\
\text { taking }\end{array}$ & I & l & $\chi_{0: 1}^{2}=18.4, \mathrm{p}<0.0001$ & 0.56 \\
\hline
\end{tabular}

664 
665

666 Table 2 Principal component analysis (PCA) of mean individual behavioral data in each 667 study was done on the correlation matrix, thus implicitly rescaling all variables, and the table

668 shows the loading scores for each of the three retained principal components. Bold typeface 669 indicates the statistically significant loadings (based on the mean inertia criterion, see main 670 text) for each variable

671

\begin{tabular}{|l|c|c|c|c|c|c|}
\hline & \multicolumn{3}{|c|}{ Study 1 (n= 39) } & \multicolumn{3}{c|}{ Study 2 (n=50) } \\
\hline Behavioral traits & PC1 & PC2 & PC3 & PC1 & PC2 & PC3 \\
\hline Movement distance & -0.460 & 0.486 & $\mathbf{0 . 6 5 9}$ & $\mathbf{0 . 7 1 4}$ & -0.450 & 0.386 \\
Mobility & -0.525 & 0.420 & $\mathbf{0 . 6 5 2}$ & $\mathbf{0 . 6 9 5}$ & $\mathbf{- 0 . 4 7 8}$ & 0.406 \\
Time spent scratching & $/$ & $/$ & $\mathbf{- 0 . 5 7 0}$ & $\mathbf{0 . 7 2 6}$ & -0.089 & 0.010 \\
Time spent basking & $/$ & $/$ & 0.335 & -0.465 & $\mathbf{0 . 6 7 1}$ & -0.122 \\
Time head hidden & 0.457 & -0.029 & 0.325 & $\mathbf{- 0 . 6 6 8}$ & $\mathbf{- 0 . 5 4 8}$ & 0.052 \\
Time body hidden & $\mathbf{0 . 9 0 6}$ & -0.034 & -0.369 & $\mathbf{- 0 . 8 1 6}$ & $\mathbf{- 0 . 5 4 4}$ & 0.045 \\
Time until basking & $\mathbf{0 . 9 0 3}$ & -0.041 & -0.303 & $\mathbf{- 0 . 7 8 7}$ & $\mathbf{- 0 . 5 4 1}$ & 0.080 \\
Absolute sociability score & 0.299 & $\mathbf{0 . 8 1 2}$ & $/$ & $/$ & $/$ & $/$ \\
Relative sociability score & 0.337 & $\mathbf{0 . 8 3 4}$ & $/$ & $/$ & $/$ & $/$ \\
Aggressiveness after exploration & $/$ & $/$ & $/$ & -0.321 & 0.303 & $\mathbf{0 . 8 2 4}$ \\
Aggressiveness after risk taking & $/$ & $/$ & $/$ & -0.284 & 0.380 & $\mathbf{0 . 7 8 4}$ \\
\hline Statistics of PC scores & \multicolumn{1}{|l|}{$/$} & 1.77 & 1.63 & 3.65 & 2.01 & 1.63 \\
\hline Eigenvalue & & 25.33 & 23.31 & 40.46 & 22.37 & 18.14 \\
\hline Variance explained & & & & & & \\
\hline
\end{tabular}


676 Fig. 1 Relationship between behavioral variation and standard metabolic rate (SMR) in male 677 common lizards $(n=39)$. A. The SMR increases significantly with body temperature. Black 678 circles represent the observed SMR values and the grey lines the predicted thermal reaction 679 norms obtained from the individual linear regressions. B. The SMR at $15^{\circ} \mathrm{C}$ is negatively 680 correlated with the PC2 score measuring correlated behavioral variation in activity and 681 sociability Fig. 2 Relationship between behavioral variation and plasma corticosterone levels in male common lizards. A. The basal corticosterone level measured in the field was positively correlated with the stress response measured in the laboratory after a handling stress. B. The residuals of the stress response regressed on the basal level of corticosterone in the field decreased marginally with PC3 score measuring behavioral variation in aggressiveness. There was one outlier for corticosterone titer (stress response > $100 \mathrm{ng} / \mathrm{mL}$ ) 


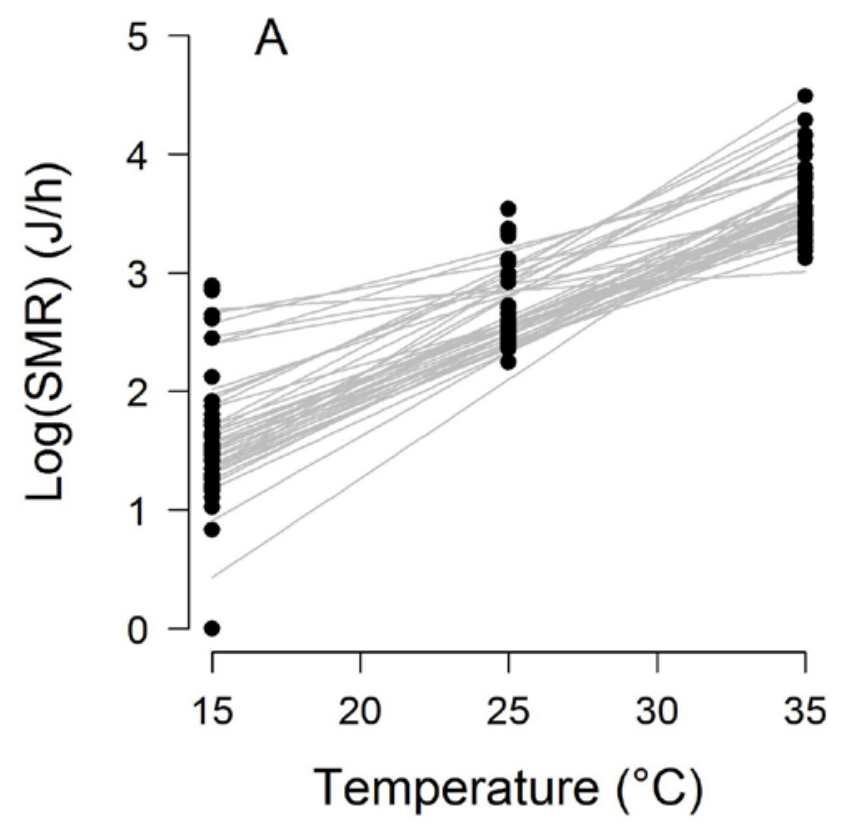

692

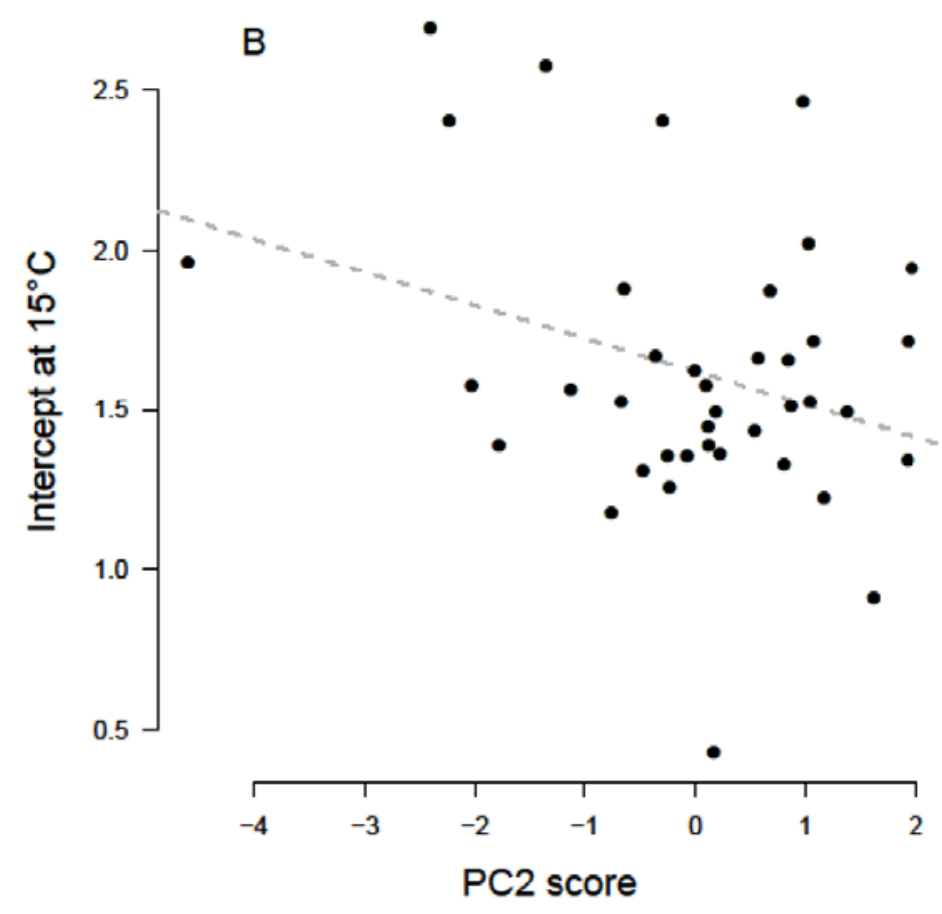

693 


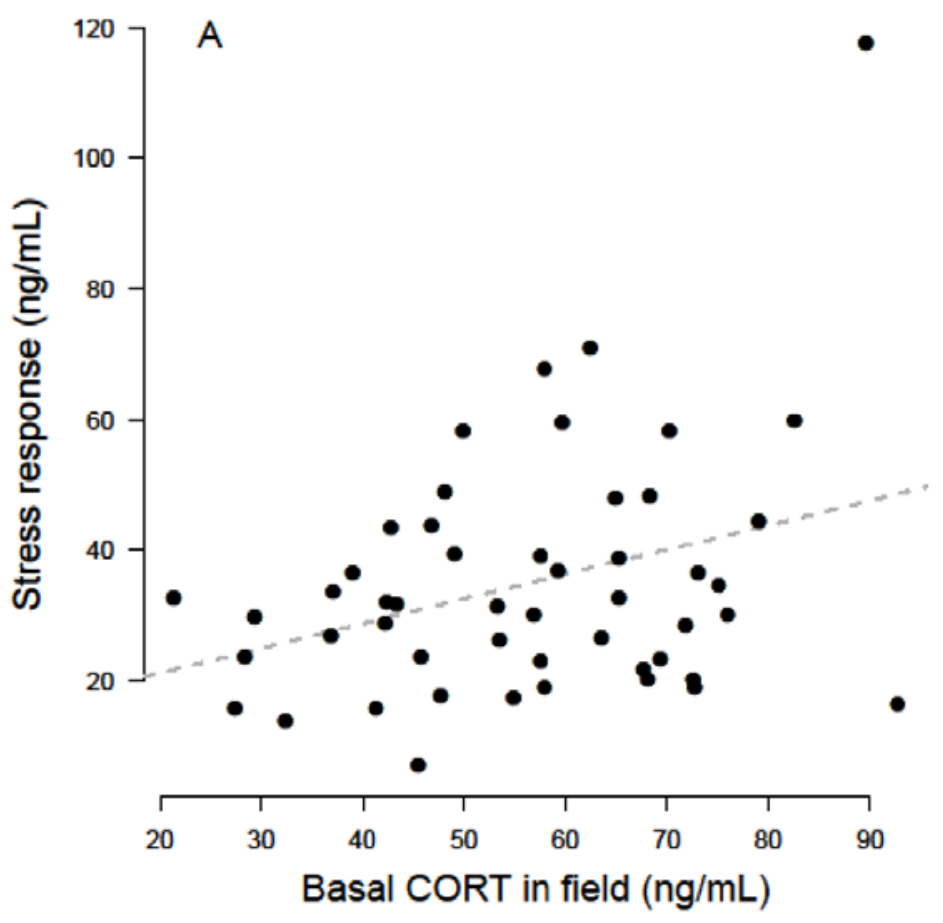

695

B

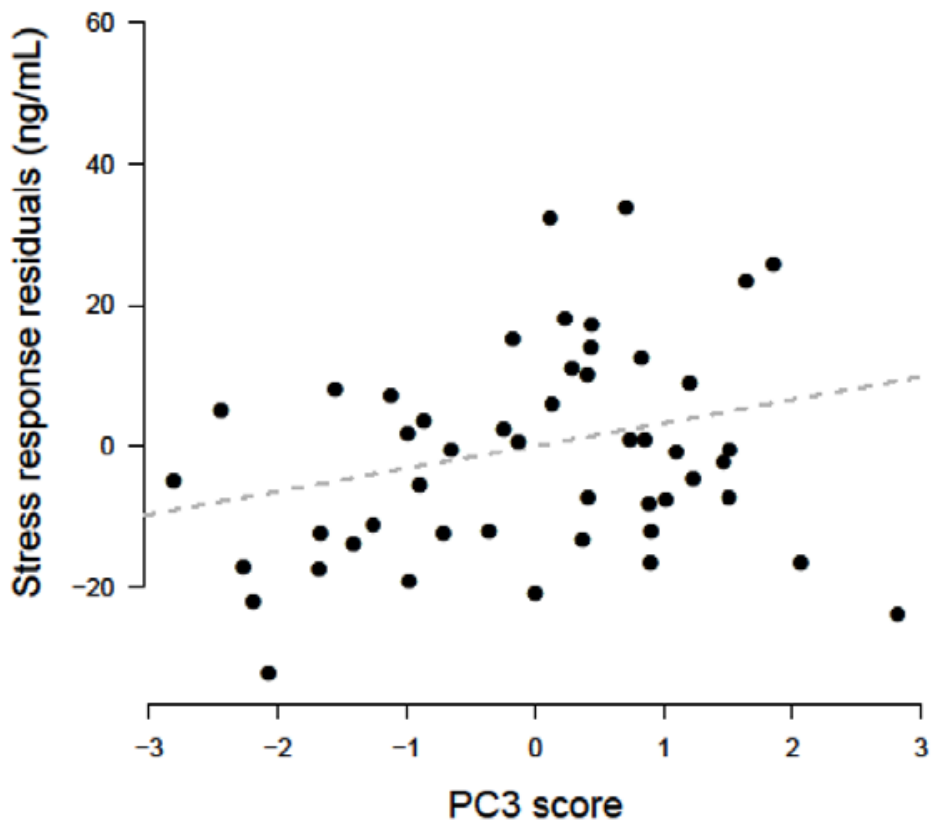

696 